\title{
El Liberalismo en Azuela
}

Q

UIEN lea la obra de Mariano Azuela, y la historia contemporánea de México, con ponderación y sin prejuicios, notará que él asume un punto de vista liberal con respecto a su pueblo y sus problemas. Azuela no sólo ha leído esa historia. La ha visto hacer; la ha vivido. Como médico militar participó en la revolución de 1910. Es, por lo tanto, un verdadero liberal - no por conveniencia o por el momento, sino por experiencia y por convicción.

Nada muy nuevo ni sorprendente se halla en las ideas liberales de Azuela. En general, sigue la gran tradición liberal del siglo XIX y principios del XX. (1) Sin embargo, en estos días de dictaduras totalitarias o comunistas, resulta interesante y a la vez estimulante leer sus novelas. No pertenece Azuela a esa lastimera clase de liberales de "biblioteca" o "intelectuales" que ruidosamente proclaman sus principios liberales tan sólo para quedar exhibidos como cobardes e hipócritas en la hora de prueba. La verdadera causa liberal en México, como en todo el mundo, ha sido dañada severamente en años recientes por falsos partidarios y profetas: la plaga de los pseudo-liberales.

En este breve ensayo falta espacio para discutir en detalle la historia y la filosofía del pensamiento liberal. En este caso, no vamos a discutir los méritos del movimiento definido que se conoce como Liberalismo Político. Más bien, basaremos el estudio en la "actitud" liberal - el liberalismo como estado mental en todas sus manifestaciones vitales. La 
expresión "ideas liberales" representa en este caso una actitud, una posición enraizada en la tolerancia, una norma justiciera sin sacrificar los principios que se tienen por justos y rectos; la capacidad necesaria para ver una cuestión desde dos puntos de vista: el pro y el contra; un interés profundo y duradero en el bienestar y el progreso de las masas, de los menos afortunados, los de abajo. La mentalidad genuinamente liberal también evita el escollo de asumir posiciones extremas y llegar al fanatismo en cualquiera forma.

Azuela calladamente sostiene la tradición liberal, la lucha por el mejoramiento social y económico, así como la libertad política e individual de las masas; persigue miras que se encuentran en los ideales, ya que no siempre en las acciones, de hombres como Hidalgo, Juárez, Madero, Zapata y, hoy en día, Cárdenas. Esa actitud es de gran importancia e interés a la luz de los acontecimientos de los últimos meses, sobre todo las elecciones generales de julio pasado.

Al hacer el estudio de las ideas liberales de Azuela surge la seria dificultad de que el gran novelista mexicano rara vez permite que determinado personaje exprese sus propias opiniones, exclusivamente. (2) Como ya lo han indicado otros críticos, Azuela rara vez se identifica en novela alguna con un personaje en particular. La única excepción a la regla -si es'que en realidad es una excepción- radica en la caracterización del gran liberal, Rodríguez, en Los caciques. En consecuencia el lector debe tener cuidado en interpretar las ideas de Azuela desde los distintos puntos de vista expresados por los muchos personajes que presenta.

El liberalismo de Azuela puede notarse con máxima claridad en los campos del pensamiento político, social, económico y religioso, con marcado énfasis en los tres primeros. En el campo de la política censura la corrupción en todas sus formas, sobre todo en la burocracia excesiva, el favoritismo y el caciquismo. El liberalismo social de Azuela se manifiesta en su odio a las distinciones de clase; en su condenación de la miseria económica de las masas y en su sátira de la educación superficial e hipócrita que recibe el pueblo. En el terreno religioso Azuela ataca los excesivos males del clerica- 
lismo, la frialdad impersonal de la caridad a base de instituciones y la hipocresía religiosa. En estos campos, pues, es donde se oye con claridad "el golpe seco del machete" literario de Azuela.

Un examen cabal de sus novelas, aunque necesariamente breve, servirá para probar la calidad y firmeza de las ideas liberales de Azuela. Procederemos con la repetida advertencia de que no hay un personaje que a exclusión de los otros hable por Azuela, y que el lector no debe llegar de improviso a la conclusión de que todas o alguna de las ideas que una multitud de personajes expresan en sus obras, son estrictamente las ideas de Azuela. Porqué tiene la costumbre de presentar muy a menudo y muy impersonalmente los dos lados en una discusión, un argumento o una disputa.

Desde su juventud Mariano Azuela se identificó en el campo de la política con el grupo liberal de oposición a Díaz. Aunque nunca fué político en sentido alguno de la palabra, ha observado cuidadosamente todos los movimientos políticos que ha habido en México durante los últimos cincuenta años. Desde su primera novela, María Luisa (1907), hasta la más reciente, Avanzada (1940) ha mostrado su interés profundo en la cambiante escena política - sobre todo en lo que llama "los grandes momentos". (3) Satiriza al político de profesión que ladinamente engaña a las masas, así como a las hipócritas y huecas clases altas y los religionarios de oficio. En Mala yer$b a$, Azuela condena el poder político y el soborno que permiten al hacendado desvirtuar la justicia. Los caciques, en su totalidad, es una novela de censura al jefe político que controla por completo la vida del pueblo.

Ya desde 1907, antes de la revolución de 1910, Azuela criticaba los trastornos políticos causados por ambiciosos politicastros. Dice en María Luisa (1907) : "Nació (María Luisa) cuando los soldados de nuestras eternas revoluciones venían a los pueblos manchados con la sangre de sus hermanos".

En Andrés Pérez, maderista (1911), el autor satiriza al capataz y se refiere acremente a su fuerza bruta como "el látigo de este mentecato capataz". La libertad de prensa era 
prácticamente nula en aquel tiempo, ya que "los redactores de oposición están en la cárcel". Los descendientes políticos de los extremadamente conservadores encomenderos son, dice uno de los personajes de Azuela, "la turba famélica insaciable de los vampiros de la raza mexicana". A don Porfirio Díaz y su régimen les encuentra parecido con una dosis de morfina que no cura y tan sólo mantiene al paciente quieto y en un estupor. Indudablemente don Octavio, en esta misma novela (Andrés Pérez, maderista) habla por Azuela cuando dice que un pueblo sólo puede ser libre cuando tiene profundo deseo de libertad y una fe perdurable en su propio derecho de existir como pueblo. Sin ese deseo de libertad, ni Madero ni la revolución valen cosa alguna. La catalepsia inducida por la morfina continuará hasta que los Estados Unidos o algún otro vecino poderoso haya transformado la catalepsia de México en una mortaja. Andrés Pérez concluye en una nota de pesimismo con la muerte de Toño Reyes y la advertencia: "Pueblo mexicano, no has triunfado; mentira". Las masas, la gente del pueblo, siguen en la misma miserable condición de antes. Dice:

"Nacieron esclavos - esclavos todavía, esclavos hasta morir; eternamente esclavos". Entre tanto, los que están en el poder y los que luchan por reemplazarles son igualmente cínicos e igualmente insolentes; tan sólo se les reconoce por "un matiz que los distingue: la insolencia indolente del cerdo gordo, y la insolencia rabiosa del cerdo flaco".

Los elementos políticos y las implicaciones que hay en Los de abajo (1915), quedan reducidos a lugar secundario por el conmovedor relato de Demetrio Macías y sus guerrilleros de las escarpadas sierras. Sin embargo, en ese fondo oscuro está la historia de un despotismo político que ejerce un gobierno que oprime a los pobres y cuyos soldados les roban hasta "el maicito que tenemos para comer". Se les prende fuego a las casas de los campesinos; se veja a sus mujeres. Los hombres, provocados a la rebelión, son fusilados donde se les encuentra: "allí los acaban como si fueran perros del mal".

En Los de abajo, Azuela vió dos aspectos de la revolución: primero, "el triunfo sublime de la Justicia", y segundo, 
creyendo ver "una florida pradera al remate de un camino", se encontró con un "pantano". Los jefes políticos son casi siempre los mismos, ya se llamen Carranza, de la Huerta o lo que sea. La lucha es contra los amos "en defensa de los sagrados derechos del pueblo, pisoteados por el vil cacique". La sátira tiene un ribete humorístico cuando Luis Cervantes, desilusionado por la derrota de Villa, y desterrado, sugiere a su ex compañero de armas en la revolución que venga luego a El Paso, Texas, donde con su guitarra pronto se convertirá en una lumbrera en las filas del Salvation Army. Mientras tanto, las masas no han cesado de luchar: "y así estamos nosotros, a reniega y reniega, y a mátenos y mátenos. Pero no hay que decirlo, compadre".

El grito de guerra del liberalismo político y lar sátira mordaz de Los caciques pueden resumirse en unas líneas tomadas de esa novela: "La plebe llenó la calle. ¡Viva Madero! ¡Mueran los caciques! 'Mueran los ladrones del pueblo!" Entre "el estampido de los 30-30", el ruido de los maussers y el galope de los caballos, arde hasta los cimientos la casa de los caciques. "La casa 'Del Llano Hnos. S. en C.', ardía muy bien". Del odio y el despojo surge una débil esperanza para las masas en tanto que el humo del edificio que arde se eleva en grandes volutas hacia el cielo.

En ninguna parte queda mejor expresada la sátira contra los politicastros y sus eternos pronunciamientos que en las páginas de Precursores (1935). En esta obra Azuela vuelve a los primeros días. Caen y suben los gobiernos, pero la suerte del pueblo es la misma. "A golpes de Estado suben y bajan los gobernantes de México: se está forjando el patrón de nuestra gloriosa democracia - Politicastros en espera siempre de alguna coyuntura para colarse, aprovechan el momento, seducen a los diputados del congreso local". Se escribieron bellos planes en defensa de todos los derechos del pueblo, tan largo tiempo buscados, contra el poder de los caciques y los grandes latifundistas hereditariòs. Pero casi nada resultó de esos planes altisonantes, dice Azuela, y luego agrega con suave sátira acerca de ellos: "en honor de los autores del Plan Regenerador hay que asentar que no dejaron noticia alguna de 
haber pretendido inventar la pólvora". Eso no quiere decir que no tiene fe Azuela en los principios fundamentales de la Revolución. Critica las teorías y los líderes falsos que no hacen más que pronunciarse.

En El camarada Pantoja (1937), Azuela da muestras del más acendrado liberalismo político y escribe su más profunda sátira. Mientras busca México un candidato a la presidencia de la república, por conducto de lá Liga de la Defensa Revolucionaria, "busca al hombre que llegue con el látigo en una mano y la torta en la otra. Busca a su hombre". Ciertamente, México ha tenido en tiempos pasados y tiene ahora, muchos dirigentes políticos incorruptibles, que de corazón se interesan por las masas. Eso demuestra Azuela. Han trabajado larga y fielmente por el mejoramiento de su patria, como lo indica Azuela en alguna otra parte de sus novelas. Pero la labor de estos dirigentes sinceros y capaces la obstaculizan demasiado a menudo, como dice uno de los personajes, "tipos de presidio, rufianes, levantados del estercolero a los puestos más altos del gobierno. Valores nuevos. Los unen los mismos gustos y aficiones; puñal, baraja, vino, mujeres y codicia de dinero, de mucho dinero".

Sin embargo, en la opinión sincera de Azuela hasta los hombres y los movimientos peores tienen algo bueno en sí, y a pesar de los peores males que han resultado de la Revolución, el movimiento no es malo. Como dice un personaje en El camarada Pantoja: "Justamente. Lo que hay de maldad en esta obra perecerá; mientras que lo mucho bueno que hay en ella perdurará en bien de los hombres". Así piensa el verdadero liberal en cuanto a los valores perdurables de la Revolución de 1910.

En San Gabriel de Valdivias (1938), uno de los peones dice de los amos políticos y los oradores: "Con dinero del trabajador y para hacer ricos a los habladores". Desgraciadamente para los trabajadores y los peones, las masas de México, el nuevo orden de cosas en la política y los sindicatos han hecho poco de valor permanente. Cambian los amos, pero como dice don Marto: "Ahora lo sé ya todo, Ciriaco. Lo que tu padre decía: 'la misma jeringa con otro palo'." Pero aña- 
de que no todos los líderes eran traidores a la causa del pueblo. Muchos se sacrificaron en la lucha.

La misma reacción liberal y el mismo pesimismo general que se encuentran en San Gabriel de Valdivias continúan en Regina Landa (1939). Reinan en el México oficial la burocracia, la hipocresía y el bluff. Regina se da cuenta de que "este señor Nava es otro de los resquicios por donde ella comenzó a asomarse al bluff que reina en las oficinas del gobierno". Los jefes cambian de color político tan rápidamente como el camaleón, lo mismo que Villeguitas, "subcacique de un pueblo rabón". Sin embargo, hay que hacer notar, por equidad, que no es México el único país donde abunda la corrupción política.

Por lo que toca al comunismo en México, Azuela le quita la existencia con la burla y la sátira que hace de los hipócritas oradores que se emborrachan con su propia palabrería y su sed de poderío. Para Azuela, son igualmente malos los extremos del comunismo y el fascismo. El joven orador comunista grita que no existe la libertad de pensamiento - "Su mentira me la demuestra el volante de mi automóvil". Miguel Angel, otro de los personajes, le hace notar en seguida a Regina: "Dice yo y mi automóvil, y es comunista". Al joven en cuestión lo describe como una "lumbrera de Juventudes de Vanguardia, obrero intelectual, redentor del proletario".

Lo que hay de trágicamente irónico para las masas en la labor de los jefes y los conductores de los sindicatos llega a su punto culminante en la más reciente novela de Azuela, Avan$z a d a$ (1940), pues en ella los dirigentes obreros comienzan a pelearse entre sí. Una vez más se traiciona a las masas de obreros y peones y se las abandona a la confusión y el desorden. Se exacerban los odios de clase hasta un grado extremadamente amargo. El joven mismo que sacrificó posición y riqueza por ayudar a la causa de los obreros es denunciado y condenado por aquellos a quienes trató de salvar. El extraviado joven se atreve a proclamar que "hasta los animales tienen derecho a comer". Por ello se le acusa de "clerical, reaccionario y fascista". El grito de batalla es ahora éste: 
"Camaradas trabajadores, ningún asunto es de tanta importancia para la vida de nuestros sindicatos como la lucha de clases". A este último clamor contesta un cínico que grita: "Te hieden los pies, camarada". De los acalorados debates nació el gran Himno del Odio. Los jóvenes extraviados no habían contado con la ferocidad de "ila lucha de clases! i La ópima cosecha del odio sembrado!"

El liberalismo social de Azuela, sus ideas sobre las condiciones sociales y económicas del pueblo mexicano, tienen muchos puntos de contacto con sus tendencias liberales en el campo de la política. Aunque más ampliamente difundidas, en todas las novelas de Azuela puede uno encontrar ideas liberales netamente expresadas sobre temas sociales y económicos. Hay más: muchas de sus novelas, desde María Luisa hasta Avanzada, están basadas casi por completo en cuestiones sociales o económicas. Sería casi imposible citar todos los casos en que Azuela indica sus tendencias al liberalismo social en sus obras. Unos cuantos ejemplos de su sátira, de su censura de las malas condiciones sociales y económicas en México durante un período de varios años y de su avanzado pensamiento liberal y social, bastarán para los fines que se persiguen en este estudio. (4)

Sin ir más lejos, su primera novela, Maria Luisa, es en su totalidad una condenación de las condiciones sociales y económicas que causaron, o cuando menos evitaron que se hiciera algo por prevenir la trágica muerte de una joven huérfana, hermosa pero demasiado romántica.

En Mala yerba (1909), Azuela presenta el caso de una familia de hacendados que viven como parásitos ociosos y dañinos de la vida y el trabajo de las clases bajas. Se censura el sistema de la hacienda, con su sangría de los pobres: "desde entonces náiden ha hecho más desgracias con los probes que estos demonches de Andrades".

Azuela siente profundamente los sufrimientos de las masas del pueblo mexicano. Eso lo demuestra a las claras en $A n$ drés Pérez. Aunque escrita sobre el tema de la revolución, esta novela condena la situación social y económica durante el largo período "de la miseria del paîs". Los millones de tra- 
bajadores mexicanos a jornal diario se ven forzados por las circunstancias a vivir "sólo de maíz y de frijol". Por término medio el obrero recibe treinta y siete centavos diarios, y el maíz se vende a siete pesos el hectólitro y los frijoles cuestan dos veces más. Esto ocurre en el año del primer centenario de la independencia de México, durante el cual "el gobierno gastó más de veinte millones de pesos en construir un teatro"... y "otros millones en banquetes a delegaciones extranjeras llamadas a celebrar la independencia política de México!"

La situación económica era tan mala que las clases más bajas estaban medio muertas de hambre. Ya más avanzada la revolución, los peones tenían que esconder el poco maíz que les quedaba en sus míseros jacales, para que no se lo llevaran los soldados. Los programas de los intelectuales para el mejoramiento de las condiciones económicas no eran prácticos, "sólo la resultante tóxico-gaseosa de la indigestión de sus lecturas" ... Los peones eran despojados continua y sistemáticamente de sus tierras heredadas "por disposición legal", y obligados a "trabajar como burros para alcanzar a mal comer apenas". Pero pronto ocurrió un cambio del régimen de Díaz: "la aurora de un cambio social". Aun en este caso la objetividad de Azuela, su sátira y su pesimismo intervienen en tanto que "a los peones se les arrulla por medio de bailes y aguardiente después de luchar por libertarse de los vampiros que siempre habrán de chuparles la sangre". Sin embargo, aunque la justicia social económica parece ser ahora una mofa, una "palabrota", aún queda alguna esperanza "en la fuerza de la raza -inmensamente más poderosa- que la fuerza de sapientísimas doctrinas". Así demuestra Azuela su fe y su liberalismo.

Las implicaciones sociales de Los de abajo son profundas y perdurables. El cuadro del indio, cuyo hogar ha sido deshecho por la guerra civil, es en verdad patético. Sobre todo las mujeres y los niños la pasan mal luchando por encontrar algo que comer. En toda la obra se ve en el fondo la triste "silueta dolorida de una mujer con su niño en los brazos". El relato humano de la novela es la historia trágica de los 
hombrecitos de la tierra atrapados sin esperanza en una lucha que en realidad no comprenden. Es la tragedia, antigua como el mundo, de la lucha civil, cruel y devastadora pero a veces necesaria. Desde el punto de vista social y económico, ambos contendientes en la pugna terminan arruinados. Se puede lograr un atisbo al interior de la sangrienta tragedia de la guerra intestina y al fondo de la sátira de Azuela en su descripción de una pelea de gallos: "la lucha fué brevísima $y$ de una ferocidad casi humana".

El cuadro que pinta sobre los aspectos sociales de la Revolución en Las moscas (1918), es bien pesimista. Aquí se demuestra la misma ciega falta de comprensión de la verdadera revolución social. Esto queda mejor expresado en este pasaje:

"En el hálito tibio de la noche llega de allá muy lejos un rumor sordo y misterioso, un rumor solemne como la voz del mar: 'México se ha salvado'-. Y en el horizonte, la luna enharinada y bizca ríe..., ríe".

La falta de un verdadero sistema educacional en México y la resultante ignorancia y superstición de las masas, las presenta Azuela vigorosamente en Los caciques (1917). "La ignorancia de las masas es la desgracia nacional. Quien no lucha contra la ignorancia es un criminal". La educación para los negocios y las finanzas ha sido singularmente descuidada dejando a México en la garra fatal y mortífera de los explotadores extranjeros que se aprovechan de sus riquezas sin importarles nada el bienestar de su pueblo. Esto lo expresa Rodríguez en Los caciques cuando dice: "el negocio es nuestro trabajo hecho dinero en el bolsillo de ellos".

El sórdido cuadro de ruina social y económica que presenta Azuela en Las tribulaciones de una familia decente (1918)', está trazado en forma excelente. Esta es la irónica tragedia de "una familia decente", un grupo de parásitos que en realidad nunca ha aprendido a trabajar. Arruinada por la Revolución, la familia se va a la capital, donde habría muerto de hambre a no ser porque el padre y una hija muy sensata se resuelven a trabajar honradamente para salvarse. Lulú, la hija, dice a la horrorizada familia: "Papá es el cajero y yo 
su taquígrafa". La nueva generación había encontrado su "vocablo salvador, el trabajo".

Como cuadro de miserable situación social y económica, La luciérnaga (1932) es la historia de un manirroto sin voluntad propia a quien arruina su propio hermano, tipo ladino, y las bandadas de cuervos que en forma de parásitos humanos llenan la capital mexicana, y, por decir la verdad, todas las capitales del mundo.

En El camarada Pantoja (1937), Azuela presenta el caso de las condiciones sociales y económicas de México causadas por la codicia y el odio de clases. Excepcionalmente interesante es la relación del papel que hacen los intelectuales, los "liberales de biblioteca", que hilan bellas teorías pero con poco práctico contribuyen para mejorar la miserable situación. Dice uno de los personajes de esta novela:

"¿Qué han hecho los intelectuales en esta obra grandiosa de renovación social? Te hablo de los intelectuales que iniciaron y encauzaron el movimiento revolucionario. Seguramente que los nobles sentimientos y los ideales se cultivan mejor con los pies calientes y el chocolate a la mesa".

"Nadie ha hecho tanto daño a México como los teorizantes", grita don Carlos en la novela San Gabriel de Valdivias. El líder obrero sin escrúpulos sigue excitando a las masas mientras que llena sus propios bolsillos a costa del pueblo. "El desecho de todo México: langosta que está acabando con la producción después de haber acabado con el productor", grita el conservador. La solución del problema está en la educación moderna y en las ciencias modernas según el ingeniero que agrega:

"El liderismo es una lacra y una fuerza como la pólvora y el acero. Pero cuando nuestra gente acabe de abrir los ojos sabrá arrojar al líder (malo) de la tierra..."

En Regina Landa, las generaciones más jóvenes entre los obreros reciben la advertencia de no luchar entre sí y de desarrollar un programa genuinamente constructivo para las masas - "higiene y cultura están al alcance de tus manos y sólo falta tomarlas". 
También en Regina Landa se encuentra la censura de la caridad organizada a base de instituciones. La crítica la hace la heroína misma cuando dice que semejante labor es "caridad sin alma, caridad mentira".

Para el novelista, ni la distribución de tierras a los indios ni la más reciente versión moderna del antiguo sistema colonial del ejido parecen resolver los problemas sociales y económicos de México en la actualidad. En la novela más reciente de Azuela, Avanzada, un joven mexicano, al regresar de los Estados Unidos, una vez terminados sus estudios, asegura a su padre que trae muchas ideas y nuevos proyectos que hay que poner a prueba. Hay que reemplazar las viejas ideas con las modernas: "Debemos abandonar estos sistemas anticuados que son verdaderos anacronismos, papá. Y si nosotros podemos hacernos ricos, nuestros peones pueden también ganarse dos o tres pesos diarios". Su padre, más experimentado, juiciosamente le dice a su ambicioso hijo:

"¿De qué le sirve al hombre ganar los bienes del mundo si descuida su alma? La ciencia ha avanzado mucho. Pero el mundo sigue cada día peor".

Debemos agregar, sin embargo, que a pesar del pesimismo de Azuela, no niega que se ha progresado en el campo económico-social en México. La Revolución no ha sido un fracaso completo a pesar de los hipócritas que medran en sus filas, porque está basada en la gran fúerza de los anhelos de la humanidad.

En el terreno del pensamiento religioso se nota claramente el liberalismo de Azuela, aunque revela menor énfasis que en el campo de lo político, lo social y lo económico. El novelista mexicano tiende definitivamente a los amplios conceptos de la religión, a sus grandes valores humanos como servicio activo para el prójimo menos afortunado. Es evidente que confía poco y dedica poco tiempo a las disputas sobre minucias, a los debates sobre interpretaciones estrechas y a los conflictos ambiciosos en pos del poderío, que han maculado el nombre del cristianismo. Bien cierto es que Azuela es enemigo del fanatismo y la gazmoñería en cualquier forma. Aunque no hay que considerarlo como expresión exacta de la actitud del novelista mismo, 
uno de los personajes de Andrés Pérez, don Octavio, dice con respecto al efecto mortífero de las falsas religiones:

"Tal vez el día que los hombres se resuelvan a limpiarse de ese cúmulo de religiones enervantes, como ahora se limpian de los microbios, alcancen al fin la salud, y con la salud la Justicia, porque sólo una humanidad sana, amigo mío, puede ser una humanidad justa".

En muchas de sus novelas, sobre todo en Precursores y El camarada Pantoja, Azuela defiende la libertad religiosa, la separación de la Iglesia y el Estado, y hace notar los males que vinieron de la vasta concentración de tierras en manos de la Iglesia.

Azuela reconoce cabalmente los méritos del padre Hidalgo y los demás preclaros sacerdotes que ayudaron al movimiento libertador original. También reconoce la labor del clero que conspiró y luchó por la causa de la revolución de 1910. Sin embargo, el clero en su mayoría -y sobre todo sus altos personajes - casi siempre se ha unido a las filas de los ultraconservadores para oponerse a las fuerzas liberales de México. Azuela respeta poco su interpretación del cristianismo y lós derechos del hombre. Viene al caso el señor cura de Los caciques, que no rechaza por completo el movimiento revolucionario porque puede restaurar muchos derechos perdidos, pero que cree que se serviría mejor a la iglesia y a Dios Nuestro Señor "si al frente de este movimiento no estuviera ese pobre hombre de Madero, que no sólo lleva la lepra del libre pensamiento, sino también la de masón, espiritista - qué sé yo cuántas cosas más".

En Las tribulaciones de una familia decente (1918), Azuela presenta el caso de la educación práctica en el terreno de la vida comercial contra la educación estrecha y gazmoña impartida por clérigos demasiado celosos: “Conque la ortiga de las ideas del siglo? Eso quiere decir que vienes del confesionario?"

La clave de la actitud de Azuela hacia la religión, y sus conceptos, se encuentra en su descripción de la bella y vivaz Pepita Balderas en Pedro Moreno, el insurgente (1935): 
"Cristiana, 'pero no gazmoña, prefiere los picantes chistes del viejo cura despreocupado a los sermones aburridos e indigestos del padre Comendador de la Merced, consejero de su familia". En otra ocasión: "El padre Comendador de la Merced ha formado una lista de americanos sospechosos: se dice que tienen pláticas muy libres y leen libros franceses". $\mathrm{Y}$ nuevamente cuando el sacerdote liberal que en secreto está ayudando al movimiento libertador confronta la mirada severa del padre Comendador: "la férrea contextura del sacerdote se derrite como una vela de sebo - bajo el peso inexorable de una simple mirada (del Comendador)".

Del breve estudio que antecede, sobre las ideas liberales y la sátira social expresadas en sus novelas, iqué conclusiones puede uno hacer sobre la calidad y el alcance del liberalismo de Azuela? Las generalizaciones son siempre peligrosas, y todavía más cuando no se puede identificar a un sólo personaje o tipo de personaje como el portavoz del autor. Azuela no se desborda en sus libros. (5) Presenta muchos puntos de vista' estudiando la cuestión por todos lados, pero el tono general de sus obras es siempre el que les imparte un ambiente liberal de veras.

Para encontrar ejemplos más específicos y pruebas más abundantes del pensamiento liberal del autor en cuestiones políticas, sociales, económicas y religiosas, basta acudir a sus novelas, como lo hemos hecho en este estudio. La base del liberalismo de Azuela es su esperanza en las masas y la simpatía que les tiene. Aquí muestra su fe en el pueblo de México, una fe a veces puesta a la sombra por el pesimismo y la duda. Los radicales de izquierda, los de "vanguardia", clasifican a Azuela como conservador y reaccionario; los conservadores extremados le consideran radical. Ese es el precio que pagan todos los verdaderos liberales cuando, conscientemente, se niegan a convertirse en paladines del punto de vista extremo en el progreso humano. (6) Azuela ha visto cómo se han traicionado los valores sociales de la Revolución una y otra vez, por las ambiciones personales de muchos de sus llamados líderes. De ese hecho nace la sátira y surgen el pesimismo y la duda del autor. 
A pesar de los adelantos logrados con el nuevo sistema de educación rural para las masas indígenas, y el adelanto seguro, aunque terriblemente lento, en el estado económico de los desvalidos, por medio de las reformas agrarias y el sistema ejidal moderno, Azuela, sigue viendo con marcado escepticismo ocasional lo que la Revolución llama su progreso social. La guerra de clases y la pugna intergremial están anulando en mucho la promesa de mejoría social y económica. Pero en tanto que otros escritores se han alejado de la Revolución, él sigue en pie, y cree que ésta debe seguir adelante hasta que dé por resultado cuando menos la libertad económica y social de los indios y las otras clases bajas de México. Tiene fe el novelista mexicano en el progreso, pero su papel de fiel observador le empuja muchas veces al pesimismo.

Se puede decir con verdad que quien no haya conocido la miseria y la necesidad no puede apreciar en toda su extensión las ideas liberales de Azuela. Por los puntos de vista expresados por todos sus personajes y tipos, se ve uno obligado a llegar a la conclusión de que Azuela no es un fiero cruzado ni un propagandista, sino más bien un observador liberal sinceramente interesado, un fiel reportero de la vida mexicana. (7) No tiene credo, programa, plan ni teoría bien definidos para lograr la salvación de México. (8) No tiene mucha fe en las bien hiladas e imprácticas teorías de los "teorizantes". Pero sí se interesa fundamentalmente en los grandes movimientos históricos y en el papel que en ellos desempeña el hombre común; plebeyo. Azuela respeta poco las verdades de la historia oficial cuando se aplican a las vidas de los hombres en una gran revolución social. "La historia oficial, ramera cobarde, entrapuja siempre la verdad", dice en Precursores. En el prefacio de esta novela, da su punto de vista sobre los dos tipos de bandoleros eternos de México:

"Hablo del bandolero auténtico (El Amito) que nunca se traicionó, del que tiene su final en la horca. El otro, el que llega a una posición brillante en la sociedad y aun logra dejar su nombre glorioso en los bronces y mármoles nacionales, me atrae apenas como cualquiera otra de las sabandijas de Dios". 
Azuela es un liberal que cree en la fuerza silenciosa de la evolución del progreso y las ideas sociales, sin negar la necesidad, en muchos casos, de una revolución. Su vida y su obra demuestran siempre su liberalismo vital y conmovedor. Es el enemigo jurado de fanáticos y fanatismos de todas clases. (9) Respeta poco o nada a la gran mayoría de los teóricos académicos y sus teorías, y cree que si bien se ha logrado algún adelanto, el problema de las masas indígenas de México sigue siendo en su mayor parte, "pura música". (10)

Finalmente, para quienes conocen íntimamente a Azuela y su obra, la profundidad y sinceridad de su liberalismo quedan mejor expresadas en sus propias palabras:

"Algunos críticos han dicho que en mis novelas de la revolución sólo he dado la mitad de la verdad, y éste es el elogio más grande que podría recibir. Pero no lo acepto porque es mentira. La verdad tiene millares de millares de facetas, y un hombre apenas puede dar en rigor la que tiene frente a sus ojos. No es pues la mitad de la verdad sino una pequeñisima parte de la verdad, la mía, la que he querido dar con la mayor honradez y fidelidad posibles". (11)

Sin duda alguna Mariano Azuela, el liberal contemporáneo más grande y más sincero de México, quisiera creer en las palabras del maestro rural en su propia novela, San Gabriel de Valdivias, que dice: "Hermano soldado, hermano campesino: México está en tus manos".

Pero el gran novelista se ve forzado a admitir: "Lo malo es que a veces sólo él se las entiende".

\section{Francis M. Kercheville, University of New York.}

(1).-Véase Kercheville, F. M., "Larra and Liberal Thought in Spain", Hispania, Vol. XIV, No 3, May, 1931, pp. 197-204. También Kercheville, F. M., and Hale, Raymond, "Ibáñez and Spanish Republicanism", Modern Language Journal, Vol. XVII, $N^{\circ} 5$, February, 1933, pp. 342-348. Véase Kercheville, "Galdós and the New Humanism", Modern Language Journal, Vol. XVI, $N^{\circ}$ 6, March, 1932, pp. 477-489. 
(2).-Véase González de Mendoza, J. M., Preliminar a Mala yerba, tercera edición, México, Ediciones Botas, 1937, p. 11.

(3).-Véase Englekirk, John E., and Kiddle, Lawrence B., excelente Introducción y edición de texto de Los de abajo (F. S. Crofts, New York, 1939).

(4).-Compárense las ideas liberales en los campos de la educación y de la economía con las obras de Rodó, Gamio, Vasconcelos y Moisés Sáenz.

(5).-Véase arriba nota número 2.

(6).-Escribe Azuela: "Soy enemigo jurado de los fanatismos, sin que me importen sus etiquetas" - excerta de una carta fechada, México, 27 de mayo de 1940 .

(7).- "Lo que he visto no me sirve para copias, sino para tomar de ello los elementos que necesito para mis novelas", dice Azuela en la misma carta mencionada en nota número 6. Además, en una carta - México, 16 de marzo de 1940- escribe Azuela: "Nunca han sido las personas sino los acontecimientos como reflejo de un estado social to que me ha interesado".

(8):-Dice Azuela: "Mi papel de reportero de la revolución me basta para dejar a un lado a los teorizantes".-Véanse notas 6 y 7.

(9). -Véase nota 6.

(10).-Excerta de la carta mencionada en nota número 6.

(11). Excerta de la misma carta de la nota número 7.

\section{BIBLIOGRAFIA}

Principales novelas de Azuela consultadas en la preparación de este estudio

Maria Luisa y otros cuentos, México, Ediciones Botas, 1938.

Mala yerba, México, Ediciones Botas, 1937.

Andrés Pérez, maderista, México, Imprenta de Blanco y Botas, 1911.

Los de abajo, Madrid, Espasa-Calpe, S. A., 1930.

Los caciques (Precedida de Las moscas), México, Ediciones de "La Razón", 1931.

Las moscas (1931; véase Los caciques).

Las tribulaciones de una familia decente, Tampico? "El Mundo" (Biblioteca series), 1918.

La luciérnaga, Madrid, Espasa-Calpe, 1932.

Pedro Moreno, el insurgente, Santiago de Chile, Editorial Ercilla, 1935.

Precursores, Santiago de Chile, Ediciones Ercilla, 1935.

El camarada Pantoja, México, Ediciones Botas, 1937. 
San Gabriel de Valdivias (Comunidad Indígena), Santiago de Chile, Ediciones Ercilla, 1938.

Regina Landa, México, Ediciones Botas, 1939.

Teatro: Los de abajo, El bubo en la noche, Del Llano Hermanos, S. en C., México, Ediciones Botas, 1938.

Avanzada, México, Ediciones Botas, 1940.

Obras criticas y generales consultadas

Beals, Carleton, Mexico-An Interpretation, New York, B. W. Huebsch Inc., 1923.

Englekirk, John E., and Kiddle, Lawrence B., Introduction to text-edition of Los de abajo, New York, F. S. Crofts and Co., 1939.

Gamio, Manuel, Mexican Immigration to the United States: A Study of Human Migration and Adjustment, Chicago, University of Chicago Press, 1930.

Gruening, Ernest, Mexico and its Heritage, New York, Century Co., 1928.

Kercheville, F. M., Véase nota No. 1 de este estudio.

Sáenz, Moisés, Some Mexican Problems (with Herbert I. Priestly), Chicago: University of Chicago Press, 1926.

Tannenbaum, Frank, Peace by Revolution, New York, Columbia Press, 1933.

Vasconcelos, José, Aspects of Mexican Civilization (with Manuel Gamio), Chicago: University of Chicago Press, 1926. 